\title{
THE CURRENT STATUS OF INDUSTRIALIZED CONSTRUCTION AND CONSTRUCTION ROBOTICS IN FINLAND
}

\author{
Lauri Koskela, Senior Researcher \\ Technical Research Centre of Finland \\ Laboratory of Urban Planning and Building Design \\ Itätuulenkuja 11 \\ SF-02100 Espoo \\ Finland
}

\section{ABSTRACT}

During the past few years, a cluster of development projects with wide participation have been initiated in Finland in order to create the necessary basis for a second wave of industrialization of construction in the next decade. The targets include the creation of an open construction system based on prefabricated components and of a national framework for project wide computer aided design. On the other hand, a research programme concerned with computerization and robotization of construction has been launched, in order to build up the necessary national competence in these areas, which are seen as the major driving forces for the coming changes.

\section{Introduction}

As in many other countries, the 1980's have been a period of structural changes for the Finnish construction industry. After succesful export endeavour in the beginning of the decade, the industry ran into serious profitability problems caused by intense domestic market share competition, in the middle of a construction boom. Simultaneously, critical voices from the clients' and users' grew louder in respect of service provided, quality and long term performance of facilities constructed.

In the mid-eighties, a process of reorientation began in the construction industry. One major conclusion has been that a strong increase in research effort is needed. Another commonly shared assumption concerns the progress of industrialization of construction: even if prefabrication is already very prominent [1], a further advancement of industrialized construction, with related automation and robotization efforts has been seen to be necessary.

Accordingly, a cluster of industry wide comprehensive development projects has been initiated. These projects strive for creating a necessary basis or infrastructure for a second wave of industrialization. on the other hand, a research programme concerned with computerization and robotization of construction has been launched, in order to build up the necessary national competence in these areas, which are seen as the major driving forces for the coming changes.

2. National Development Projects Related to Industrialization and Computerization of Construction

The project "RATA 2000" (Construction Method 2000) is an umbrella project, by means of which a framework or basis for component based industrialization will be set up. This project, which will be carried out in 1988 - 1989, has three subprojects. The first will deal with the cost structure of various construction methods, 
and a number of alternate development strategies (focussing, for example, on prefabrication, specialized subcontracting or quality) will be formulated. The second subproject considers design of prefabricated buildings, and results in a design guideline. The third subproject analyzes requirements for the construction process and for the project organization set by utilization of prefabricated components. The project is administered by the Technical Research Centre of Finland.

On the basis of the results of the "RATA 2000", material specific development projects have been or will be initiated for precast concrete construction, masonry structures, steel frame construction and wood based construction. The project for precast concrete component construction of housing and office buildings "TAT", started in 1986 and will be finished in 1991. The project further develops the Finnish BES-system, an open concrete component system set up in the 1960's and 1970's.

The major development targets in the TAT-project are new architectonic expressiveness, design flexibility without restrictions set by production technology, and increased freedom in layout and alterations. In June 1988, a catalogue of technical systems and components on various hierarchic levels (building, parts of buildings, modules, parts) will be presented. In the end of 1988, design guidelines will be drawn up and the planning of pilot construction projects will be commenced.

The project "Miljö 2000" (Living milieu 2000) focuses on the utilization of new construction technology in the creation of good quality urban environment. The research will both present targets for technological development and apply and test results of it. Thus the project, which has a strong architectonic emphasis, will end up in pilot building projects, connected to, for example, the TAT-project.

The ESSU project (Esthetical environment and new design techniques) is a longer term endeavour, aiming at clarifying the position of esthetical analysis in the design process and the possibilities provided by, as well as restrictions posed by the new CAD tools in respect of such an analysis. The basic motivation behind the project has been the fear of reduced environmental quality as a result of unimaginative and mechanistic approach in industrialized and computerized construction.

The main aim of the RATAS project is to define the basic structure of the computing environment of the construction industry in the early 1990's. The first phase resulted in a visionary model of what the computer aided design and building process of the 1990's should look like [2]. The second - and principal - phase of RATAS was completed in the beginning of 1988. The work was carried out in four expert groups, which have considered, respectively, - general data bases

- data exchange methods

- definition of a standard project data base structure

- new types of design documents and the design process.

It is the aim to define the common RATAS framework in sufficient detail to allow software developers to create commercial products based on it. The third phase of RATAS will cover pilot use of such software. 
3. The Research Programme "Information and Automation Systems in Construction"

The research programme "Information and Automation Systems in Construction" is concerned with the applications of knowledge engineering, robotics and integrated information systems in construction. The programme has been initiated by the Technical Research Centre of Finland, which also provides two thirds of the funds. Thus, it is more basic research and long term oriented than the projects mentioned above.

The principal objective of the research programme is to establish in Finland the competence to adapt and develop construction information and automation techniques. In practical terms, the aim is to develop new construction information and automation techniques, within chosen spheres in close co-operation with other related national development projects mentioned above.

The main emphasis in the programme is on demonstration and pilot systems, by which empirical knowledge of various techniques as well as of the systems' further development needs and user interfaces can be gained.

The programme consists of three projects. The first project considers computer integrated construction. The core task is to define and test a national structure for a construction project database, based on ideas of object oriented programming. Other tasks include specification of objectives, principles and guidelines for computer integrated construction and development of a construction material knowledge system interfaced with the project data base structure.

The second project deals with construction management systems. The aim is to specify a target model for construction management systems to be widely implemented in the $1990^{\prime} \mathrm{s}$. Special emphasis is laid on analyzing the potential of knowledge representation, simulation and animation, as well as on development of interfaces between design and construction management data bases and between construction management systems and construction machines.

The third project, which focusses on construction robotics and production automation, will be presented below.

\section{Research and development of construction robotics}

Research and development of on-site construction robotics is in an introductory phase in Finland. However, on the related field of tunnelling a number of automated drilling and spraying machines have been developed and commercialized. Automation concepts have also been applied in factories for precast concrete components [4].

As for the actual construction robotics, a prestudy on the status of the technology was prepared in 1986 by the Technical Research centre of Finland [3].

In 1987, a Norwegian-Finnish feasibility project of construction robotics was started. The project is realized by the Technical Research Centre of Finland, Norges byggforskningsinstitut (NBI) and senter for Industriforskning (SI). The aim of this project is to determine and evaluate the most suitable robotization projects from the point of view of the construction industries in respective 
countries. From Finland, fourteen firms participate in this project.

After initial screening, nine construction robotics ideas have been chosen for further analysis. These include, for example, crane automation, automation in prefabrication, spraying robot in inner works, equipment for materials handling and storage on site, and masonry robotics. The project will end up in detailed plans for development of the most promising construction robotization themes.

The next phase of construction robotics development will be realized in the framework of the research programme "Information and automation systems in construction", described above. From the robotization themes of the feasibility project, some will be picked up for further development. The focus will be on adaptation and testing of critical technologies, such as navigation, mobility, sensing and goal driven performance, by experimental robots, as well as on clarification of requirements imposed by robotization on construction materials and components. One specific objective is to develop measurement and control methods and devices as well as information systems for the precasting of hollow-core slabs.

\section{Conclusions}

The emergent Finnish strategy towards automated and robotized construction stresses in the short term, on industry wide efforts for creating an open, material independent building system, and a common framework for computerization of design and building process. The subsequent task is to build up the necessary national competence in construction robotics and related fields, in order to be capable of promptly adapting and implementing the new technological possibilities in the 1990's. One key issue is to achieve synergy between development of construction systems and automation systems.

Acknowledgements

This report has been prepared in the framework of the research programme "Information and Automation Systems in Construction".

\section{References}

1. Industrialization of Building in Finland. Tampere University of Technology. Section of Construction Economics. Tampere 1985. $41 \mathrm{p}$.

2. Leppänen, Pekka \& Sarja Asko. Preliminary Models for Computer Aided Building Design and Construction Management Process. Technical Research Centre of Finland. Research Notes 606. Espoo 1986. $47 \mathrm{p}$.

3. Salo, Esko \& Koskela, Lauri. Construction robotics. Present status and prospects. Technical Research centre of Finland. Research Notes 746. Espoo 1987. 108 p. (In Finnish).

4. Ranta, Jukka \& al. Experiences from automation of a concrete component factory and from a mechatronic machine tool. Automation Days 87, Helsinki 12.-14.5.1987. Finnish Society of Automatic Control. Pp. 451 - 467. (In Finnish). 